КОРРЕКЦИЯ ТРАНСПОРТА КИСЛОРОДА И МЕТАБОЛИЧЕСКИХ НАРУШЕНИЙ ПРИ ОСТРЫХ
ОТРАВЛЕНИЯХ ВЕЩЕСТВАМИ НЕЙРОТРОПНОГО ДЕЙСТВИЯ

\author{
Г. А. Ливанов, Б. В. Батоцыренов, А. Н. Лодягин,
} М. В. Александров, Х. В. Батоцыренова, В. Н. Мирошниченко

НИИ скорой помощи им. И. И. Джанелидзе, Санкт-Петербург;

Федеральное государственное учреждение науки;

Институт Токсикологии Федерального медико-биологического агенства России, Санкт-Петербург;

Городская клиническая больница скорой медицинской помощи им. В. В. Ангапова, Улан-Удэ

\title{
Correction of Oxygen Transport and Metabolic Disturbances in Acute Poisoning by Neurotropic Substances
}

\author{
G. A. Livanov, B. V. Batotsyrenov, A. N. Lodyagin, M. V. Aleksandrov, \\ Kh. V. Batotsyrenova, V. N. Miroshnichenko
}

I. I. Dzhanelidze Research Institute of Emergency Care, Saint Petersburg Institute of Toxicology, Federal Biomedical Agency of Russia, Saint Petersburg

V. V. Angapov City Clinical Hospital of Emergency Care, Ulan-Ude

\begin{abstract}
Цель настоящей работы - изучить возможность фармакологической коррекции с помощью препаратов перфторана и цитофлавина нарушений кислородотранспортных систем и метаболических процессов у больных в критическом состоянии вследствие острых отравлений нейротропными ядами. Материалы и методы. У 62 больных с наиболее тяжелыми формами острых отравлений нейротропными ядами исследованы метаболические последствия тяжелой гипоксии: свободнорадикальных процессов и эндогенной интоксикации. Результаты. В результате проведенных исследований установлено, что гипоксия и метаболические изменения ведут к развитию эндотоксикоза. Усугубление явлений эндотоксикоза, в свою очередь, усиливает гипоксические повреждения. Таким образом, основной задачей интенсивной терапии в данных условиях, является восстановление доставки кислорода, снижение нарушений метаболизма и эндотоксикоза. Рассмотрены пути коррекции гипоксии и нарушений метаболизма при тяжелых формах острых отравлений. Ключевые слова: острые отравления, нарушения транспорта кислорода, перекисное окисление липидов, сукцинат, перфторан, цитофлавин.
\end{abstract}

Objective: to examine the capacities of pharmacological correction of impairments in oxygen-transporting systems and metabolic processes with perfluorane and cytoflavin in critically ill patients with acute intoxication with neurotropic poisons. Subjects and methods. Metabolic sequels of severe hypoxia, free radical processes, and endogenous intoxications were studied in 62 patients with the severest acute intoxication with neurotropic poisons. Results. The studies have established that hypoxia and metabolic changes lead to the development of endotoxicosis. Intensifying endotoxicosis in turn enhances hypoxic lesion. Thus, the major task of intensive care is to restore oxygen delivery and to diminish metabolic disturbances and endotoxicosis. Ways of correcting hypoxia and metabolic disturbances are considered in the severe forms of acute poisoning. Key words: acute intoxication, impaired oxygen transport, lipid peroxidation, succinate, perfluorane, cytoflavin.

Формирование критического состояния при тяжелых формах острых отравлений нейротропными ядами обусловлена развитием токсикогипоксической энцефалопатии (ТГЭ) с нарушениями центральной регуляции дыхания и газообменных функций легких. Это ведет к расстройствам процессов доставки кислорода к тканям организма и является пусковым в развитии критического состояния [1-3]. Прямым следствием такого рода является развитие эндотоксикоза $[3,4]$. Следует отметить, что при острых отравлениях гипоксия носит смешанный характер $[5,6]$. Одним из ее проявлений является снижение кислородной емкости крови, что, в свою очередь, ведет к увеличению напряжения функции систем, ответственных за транспорт кислорода, что при сохранении адаптивных возможностей организма проявляется в развитии гипердинамического типа центральной гемодинамики, централизации кровообращения и др. При поражении ядами общетоксического действия процессы дезадаптации протекают еще острее. Углубление процессов гипоксии приводит к срыву адаптивных механизмов. Недостаточность кислородтранспортных систем, снижение процессов доставки кислорода к тканям на фоне повышения их кислородного запроса усиливают процессы, ведущие к гипоксии тканей, наблюдаемой уже с момента поступления больных в стационар [3]. С этого момента основ- 


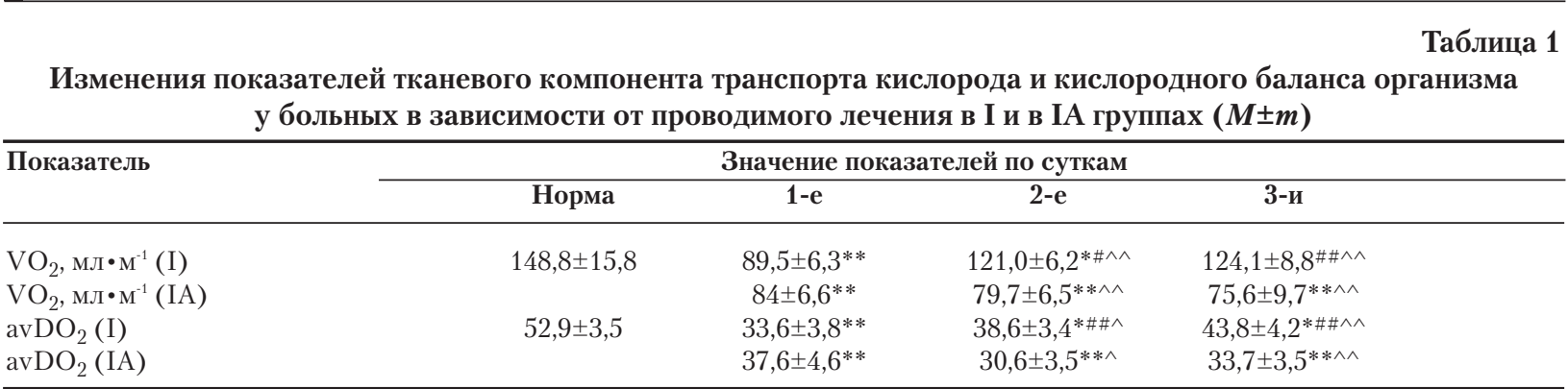

Примечание. ${ }^{*}-p<0,05$ от нормы; ${ }^{* *}-p<0,01$ от нормы; ${ }^{*}-p<0,05$ от исходных значений; \#\# $-p<0,01$ от исходных значений; $\wedge-p<0,05$ между (I) и (IA); ${ }^{\wedge}-p<0,01$ между (I) и (IA).

ным звеном патогенеза острого отравления становится дефицит энергии, связанный с переходом обмена на менее энергетически выгодный анаэробный путь с нарушениями сопряжения процессов окисления и фосфорилирования. Состояние продолжительной гипоксии органов становится фактором прогрессирующего торможения всех энергозависимых процессов.

Таким образом, общим конечным результатом действия нейротропных ядов является развитие гипоксии тканей с активацией свободнорадикального окисления и нарушениями функции системы антиоксидантной защиты.

Цель настоящей работы - изучение влияния фармакологических препаратов перфторана и цитофлавина на нарушения метаболических процессов у больных в критическом состоянии вследствие острых отравлений нейротропными ядами.

\section{Материалы и методы}

Исследование проводили в условиях отделения реанимации Центра лечения острых отравлений НИИ Скорой помощи у больных с наиболее тяжелыми формами острых отравлений смесью нейротропных ядов (в состав смесей входили лекарственные препараты из группы снотворных, нейролептиков, трициклических антидепрессантов, транквилизаторов), в 71\% случаев отравления сопровождались алкогольной интоксикацией. Тяжесть состояния больных определялась глубиной поражения мозга и длительностью пребывания в критическом состоянии. Объективизация тяжести состояния больных про-

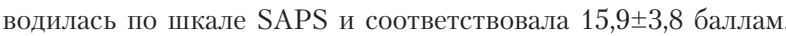
Распределение больных по группам осуществлялось следующим образом: I группу составили больные, в интенсивную терапию которых были включены метаболический антигипоксант цитофлавин -24 человека, группу сравнения (IA) составили 14 больных, аналогичные по тяжести острых отравлений. II группу составили наиболее тяжелые больные, в интенсивную терапию которых было включено сочетанное использование перфторана и цитофлавина -12 человек, группу сравнения (IIA) составили 12 больных, аналогичных по тяжести состояния, в этой группе оценка тяжести состояния по шкале SAPS составила 21,3 $\pm 2,3$ балла.

Сопоставимость групп исследования обеспечивалась: 1) исключением из групп исследований пациентов, имеющих тяжелую соматическую патологию (хронические заболевания сердечно-сосудистой и дыхательной систем, патологию ЦНС); 2) отсутствием различий между группами по возрасту (из групп исключали пациентов моложе 18 и старше 60 лет). Всем больным проводилась интенсивная терапия, включающая проведение ИВЛ, с целью снижения уровня экзотоксикоза проводились методы хирургической гемокоррекции, инфузионная, антибактериальная и симтоматическая терапии.
Перфторан вводили 1 раз при поступлении больных в стационар в объеме 400 мл внутривенно капельно. После инфузии перфторана проводили инфузию цитофлавина внутривенно капельно на 400 мл 5-10\% раствора глюкозы медленно в объеме 20 мл. Начиная со 2-х суток исследования в интенсивной терапии использовали инфузию цитофлавина в объеме 20 мл в таком же разведении 2-3 раза в сутки в течении 5 суток нахождения больных в стационаре.

Исследование кислородного баланса и кислотно-основного состояния проводили на момент поступления, через 1 час после инфузии перфторана и цитофлавина, на 2-е и 3-и сутки нахождения больных в стационаре. Определяли парциальное давление $\mathrm{O}_{2}$ и $\mathrm{CO}_{2}$ в выдыхаемом воздухе, в артериальной и смешанной венозной крови, $\mathrm{pH}$ артериальной и смешанной венозной крови. Расчетные параметры газообмена, системы транспорта кислорода и КОС получали, используя формулы, приведенные в монографии Г. А. Рябова [1988]. Уровень лактата и пирувата определяли на 1-е, 2-е и 3 -и сутки.

В эритроцитах пациентов проводили определение ряда показателей системы глутатиона и процессов ПОЛ: концентрации восстановленного глутатиона (ВГ), сульфгидрильных групп белков (СГ), малонового диальдегида (МДА) и активности глюкозо-6- фосфат-дегидрогеназы (Г-6-Ф-ДГ), глутатионредуктазы (ГР), глутатион-пероксидазы (ГП) и каталазы.

Уровень эндогенной интоксикации оценивали путем определения содержания веществ низкой и средней молекулярной массы (ВНСММ) и концентрации олигопептидов (ОП) в эритроцитах артериальной и венозной крови и в моче [7].

Проверка статистических гипотез осуществлялась на основе непараметрических методов (Манна-Уитни, Вальда, Колмогорова-Смирнова). Критерием статистической достоверности получаемых выводов мы считали общепринятую в медицине величину $p<0,05$.

\section{Результаты и обсуждение}

При исследовании показателей транспорта кислорода были выявлены нарушения всех его звеньев, что, в конечном счете, проявлялось в развитии тканевой гипоксии, регистрируемой снижением артериовенозной разницы до 63,5\%, потребления кислорода до 57,8\% от показателей здоровых лиц, повышении уровня лактата в 5,5 раз и пирувата в 2,1 раз выше нормы. Применение цитофлавина приводило к тому, что к 3-м суткам снижались проявления гипоксии тканей, что характеризовалось улучшением показателей, отражающих утилизацию кислорода тканями: наблюдали рост артериовенозной разницы по кислороду до 84,7\%, потребления кислорода до 82,8 \%, тогда как в группе без применения метаболических антигипоксантов отличий исследуемых показателей от первых суток выявлено не было (табл. 1). 
Динамика изменений показателей глутатион-зависимой антиоксидантной системы, сопряженных биохимических систем и активации процессов перекисного окисления липидов в эритроцитах при использовании цитофлавина $(M \pm m)$

\begin{tabular}{|c|c|c|}
\hline \multirow[t]{2}{*}{ Показатель } & \multicolumn{2}{|c|}{ Значение показателей по группам больных } \\
\hline & I $(n=24)$ & IA $(n=14)$ \\
\hline \multicolumn{3}{|c|}{ 1-е сутки } \\
\hline МДА, нмоль/г НЬ & $11,20 \pm 0,69^{*}$ & $9,68 \pm 1,16$ \\
\hline ВГ, мкмоль/г Нb & $2,734 \pm 0,235$ & $2,822 \pm 0,239$ \\
\hline ГП, мин/(мин•г Нb) & $0,515 \pm 0,055$ & $0,527 \pm 0,095$ \\
\hline Каталаза, ммоль/(мин•гНb) & $33,3 \pm 4,1$ & $32,1 \pm 2,7$ \\
\hline ГТ, мкмоль/(мин•г Нb) & $137,8 \pm 24,3^{*}$ & $128,1 \pm 16,4^{*}$ \\
\hline СГ, мкмоль/г Нb & $19,6 \pm 1,9$ & $17,1 \pm 2,7$ \\
\hline Г-6-ФДГ, мкмоль/(мин•г Нb) & $46,4 \pm 4,7$ & $44,6 \pm 5,6$ \\
\hline ГР, ммоль /(мин•гНb) & $183,2 \pm 24,3^{*}$ & $125,8 \pm 20,9^{*}$ \\
\hline \multicolumn{3}{|c|}{ 3-и сутки } \\
\hline МДА, нмоль/г Нb & $8,74 \pm 0,72^{*}$ & $11.3 \pm 1,1^{*}$ \\
\hline ВГ, мкмоль/г Нb & $3,29 \pm 0,28^{*}$ & $2,682 \pm 0,257^{*}$ \\
\hline ГП, мин/(мин•г Нb) & $0,681 \pm 0,06$ & $0.547 \pm 0,044$ \\
\hline Каталаза, ммоль/(мин•гНb) & $43,5 \pm 2,69^{*}$ & $35,3 \pm 2,51^{\#}$ \\
\hline ГТ, мкмоль/(мин•г Нb) & $159,9 \pm 7,5^{*}$ & $93,5 \pm 15,8^{* \#}$ \\
\hline СГ, мкмоль/г Нb & $22,8 \pm 3,3$ & $18,8 \pm 3,1$ \\
\hline Г-6-ФДГ, мкмоль/(мин•г Нb) & $59,7 \pm 5,5^{*}$ & $47,4 \pm 4,8^{*}$ \\
\hline ГР, ммоль/(мин•гНb) & $173,5 \pm 15,6^{*}$ & $135,7 \pm 14,4^{*}$ \\
\hline
\end{tabular}

Примечание. * - достоверность отличия $p<0,05$ при сравнении показателей I и IА групп; \# - достоверность отличия $p<0,05$ по сравнению с показателями 1-х суток.

Исследования показали, что параллельно с развитием гипоксии тканей развиваются процессы, связанные с энергодефицитом и нарушениями внутриклеточного гомеостаза. Принимая во внимание мнение о нарушении процессов перекисного окисления липидов как важного механизма формирования эндогенной интоксикации [8-11], а также признавая значимость угнетения систем антиоксидантной и антирадикальной защиты и активации свободнорадикальных процессов в развитии накопления токсичных интермедиатов, в частности малонового диальдегида [12-14], можно предположить, что активация процессов ПОЛ, наряду с другими механизмами, играет существенную роль в развитии эндотоксикоза.

Проведенные ранее исследования [15, 16] указывают на то, что динамика изменений состояния системы глутатиона и процессов ПОЛ в эритроцитах пациентов с острыми тяжелыми отравлениями нейротропными ядами достаточно объективно отражает не только тяжесть состояния больного, но и эффективность проводимого лечения. При этом одним из наиболее информативных показателей является содержание МДА в эритроцитах отравленных лиц и динамика его изменений. Снижение уровня МДА в эритроцитах пациентов в процессе проводимого лечения может свидетельствовать о восстановлении функции антирадикальной защиты и ряда мембранных процессов в тканях.

Определение концентрации МДА в эритроцитах отравленных позволило выявить существенные различия в динамике изменений данного показателя у лиц, леченных с использованием цитофлавина и без его применения. В эритроцитах лиц I группы имелась выраженная тенденция к снижению концентрации продуктов ПОЛ к 3-м суткам нахождения в стационаре - в среднем на
22,0\% по сравнению с показателями 1-х суток. В то время как у пациентов группы сравнения на 3-и сутки отмечалось повышение концентрации продуктов пероксидации липидов в эритроцитах на 14,3\% по сравнению с показателями 1-х суток лечения. Данные изменения могут служить прямым доказательством того, что использование метаболических антигипоксантов в терапии отравлений нейротропными ядами приводило к снижению интенсивности протекания процессов ПОЛ (табл. 2).

Факт снижения содержания МДА в эритроцитах пациентов I группы свидетельствует о наличии антиоксидантных свойств у данного препарата. Тем не менее, механизм антиоксидантного действия может быть раскрыт лишь при исследовании состояния системы антиоксидантной защиты. Наиболее важным показателем оценки состояния данной системы является концентрация восстановленного глутатиона (ВГ) в клетке.

Применение цитофлавина при лечении острых тяжелых отравлений нейротропными ядами позволяло предотвратить снижение содержания ВГ в эритроцитах пациентов, которое достигало максимума у больных, не получавших препарата, на 3-и сутки нахождения в стационаре - на 7,5 \% по сравнению с 1-и сутками. Кроме того, на 3-и сутки в эритроцитах больных I группы отмечалась тенденция к росту содержания ВГ по сравнению с 1-и сутками исследования, что также не отмечалось в эритроцитах лиц ІА группы.

Применение цитофлавина в комплексной терапии отравлений нейротоксическими агентами приводило к повышению активности глутатион-пероксидазы и каталазы в эритроцитах на 3-и сутки или частично препятствовало снижению активности глутатион-S-трансферазы в эти сроки. 
Изменения содержания веществ низкой и средней молекулярной массы (ВНСММ) и концентрации олигопептидов (ОП) в плазме и в эритроцитах артериальной крови и моче в I и в IА группах больных $(M \pm m)$

\begin{tabular}{|c|c|c|c|c|}
\hline \multirow[t]{2}{*}{ Показатель } & \multirow[b]{2}{*}{ Норма } & \multicolumn{3}{|c|}{ Значение показателей на этапах исследования } \\
\hline & & $1-\mathrm{e}$ & $2-\mathrm{e}$ & 3-и \\
\hline ВНСММ вена эр., (I) & $22 \pm 3$ & $44,1 \pm 2,6^{\# \#}$ & $39,4 \pm 1,7 \# \# * \wedge$ & $36,8 \pm 1,9^{\# \# * * \wedge \wedge}$ \\
\hline ВНСММ вена эр., (IA) & $22 \pm 3$ & $42,5 \pm 2,9^{\# \#}$ & $44,5 \pm 2,8^{\# \# \wedge}$ & $41,1 \pm 1,4^{\# \# \wedge \wedge}$ \\
\hline ВНСММ арт. эр., (I) & $20 \pm 1,5$ & $48,8 \pm 3,5^{\# \#}$ & $40,4 \pm 2,1^{\# * \wedge}$ & $33 \pm 2,2^{\# * * \wedge \wedge}$ \\
\hline ВНСММ арт. эр., (IA) & $20 \pm 1,5$ & $46,5 \pm 3,5^{\# \#}$ & $48,8 \pm 3,5^{\# \# \wedge}$ & $46,5 \pm 2,2^{\# \# \wedge \wedge}$ \\
\hline ВНСММ моча, (I) & $33 \pm 5$ & $29,8 \pm 3,8$ & $39,8 \pm 3,2^{* \wedge}$ & $44,1 \pm 2,9^{* \wedge \wedge}$ \\
\hline ВНСММ моча, (IA) & $33 \pm 5$ & $36,1 \pm 4,8$ & $29,7 \pm 6,6^{* \wedge}$ & $33,4 \pm 5,7^{* \wedge \wedge}$ \\
\hline ОП вена эр. (I) & $0,27 \pm 0,02$ & $0,52 \pm 0,03^{\# \#}$ & $0,46 \pm 0,02^{* \# \# \wedge \wedge}$ & $0,38 \pm 0,02 * * \# \wedge \wedge$ \\
\hline ОП вена эр. (IA) & $0,27 \pm 0,02$ & $0,54 \pm 0,03^{\# \#}$ & $0,55 \pm 0,03^{\# \# \wedge \wedge}$ & $0,53 \pm 0,03^{\# \# \wedge \wedge}$ \\
\hline ОП арт.эр. (I) & $0,24 \pm 0,03$ & $0,52 \pm 0,04^{\# \#}$ & $0,44 \pm 0,02^{* \# \# \wedge \wedge}$ & $0,38 \pm 0,02 * * \# \wedge \wedge$ \\
\hline ОП арт.эр. (IA) & $0,24 \pm 0,03$ & $0,57 \pm 0,03^{\# \#}$ & $0,58 \pm 0,03^{\# \# \wedge \wedge}$ & $0,51 \pm 0,04^{\# \# \wedge \wedge}$ \\
\hline ОП моча (I) & $0,3 \pm 0,1$ & $0,26 \pm 0,03$ & $0,41 \pm 0,04^{* \wedge \wedge}$ & $0,42 \pm 0,02^{* \wedge \wedge}$ \\
\hline ОП моча (IA) & $0,3 \pm 0,1$ & $0,31 \pm 0,04$ & $0,3 \pm 0,05^{\wedge \wedge}$ & $0,35 \pm 0,04^{\wedge \wedge}$ \\
\hline
\end{tabular}

Примечание. I группа - больные, получавшие цитофлавин и стандартную интенсивную терапию, ІА группа - больные, получавшие стандартную интенсивную терапию; \# - различия с нормой достоверны $(p<0,05)$; * различия с исходными данными достоверны $(p<0,05) ;^{\wedge}-$ различия (I) группы от (IA) $(p<0,05)$.

Действительно, активность глутатион-пероксидазы в эритроцитах пациентов I группы на 3-и сутки повышалась по сравнению с показателем у этих больных на 1-е сутки нахождения в стационаре, тогда как у пациентов IA группы роста активности этого фермента не отмечалось. Соответственно, если исследование активности ГП в эритроцитах в 1-е сутки не выявляло отличий между показателями лиц I и IА групп, то на 3-и сутки активность этого фермента в эритроцитах пациентов, получавших цитофлавин, превышала соответствующие показатели лиц ІА группы (табл. 2).

Аналогичные данные были получены при исследовании активности каталазы. При определении данного показателя в 1-е сутки отличий в обеих группах не отмечалось. В дальнейшем в эритроцитах пациентов, не получавших цитофлавин, практически отсутствовала положительная динамика изменения активности данного фермента. Тогда как в эритроцитах пациентов I группы активность каталазы достоверно повышалась (табл. 2).

В настоящее время большинство авторов идентифицируют эндогенную интоксикацию с увеличением количества молекул средней массы, которые выступают маркерами синдрома [7, 17-19].

У больных в ранние сроки отравления отмечено повышение факторов вторичной аутоагрессии, что подтверждает известное мнение, что острые тяжелые отравления сопровождаются развитием эндотоксикоза уже с 1-х часов острого отравления [3, 4]. Отсутствие различия между содержанием ВНСММ в венозной и артериальной крови свидетельствовали о поражении метаболических функций легких [20].

На 3-и сутки в I группе отмечено снижение веществ низкой и средней молекулярной массы (ВНСММ) во всех исследуемых средах в отличие от исходного состояния и группы сравнения. В группе IA coдержание маркеров токсемии на 3-и сутки продолжало оставаться высоким и не отличалось от исходного состояния, что подтверждает положение о том, что эндотоксемия при острых отравлениях веществами нейротропного действия, не обладающими общетоксическими эффектами, является следствием гипоксических повреждений, а не прямого токсического действия яда, так как к этому времени концентрация ксенобиотика в средах организма резко снижалась.

Увеличение концентрации олигопептидов (ОП) в артериальной, смешанной венозной крови и моче также является свидетельством наличия эндотоксикоза у больных с острыми отравлениями. Повышение концентрации ОП является результатом активации процессов неуправляемого протеолиза, развивающего нередко у больных в критических состояниях [21-23].

При острых отравлениях нейротропными ядами отмечен рост концентрации ОП во всех исследуемых средах, подтверждающий наличие тяжелой эндогенной интоксикации. Наличие положительной артериовенозной разницы по концентрации олигопептидов свидетельствовало не только о поражении недыхательных функций легких, но и о том, что сами легкие являются источником эндотоксикоза. Эффекты цитофлавина проявились на 2-е сутки терапии и характеризовались снижением концентрации ОП в плазме и на эритроцитах артериальной и венозной крови со снижением положительной артериовенозной разницы по концентрации олигопептидов. Особенно следует отметить повышение концентрации олигопептидов в моче, что свидетельствовало об активации процессов их экскреции (табл. 3).

Исходя из вышеизложенного, очевидно, что применение метаболических антигипоксантов, наряду со снижением проявлений тканевой гипоксии и ее последствий, стабилизации энергетического статуса организма ведет к снижению степени эндотоксикоза. Полученные данные согласовались с улучшением течения 
Клинические критерии эффективности цитофлавина в группе больных, с включением в интенсивную терапию цитофлавина (I) и в группе сравнения (IA)

\begin{tabular}{lcr}
\hline Показатель & I группа (n=24) & IA группа ( $\boldsymbol{n = 1 4 )}$ \\
\hline Возраст больных, годы & $38,7 \pm 6,6$ & $36,8 \pm 7,7$ \\
Время экспозиции яда, часы & $12,9 \pm 5,2$ & $14,5 \pm 5,7$ \\
Длительность коматозного состояния, часы & $39,8 \pm 8,2^{*}$ & $59,5 \pm 8,1^{*}$ \\
Частота развития вторичных легочных осложнений & $8(30 \%)$ & $8(57,1 \%)$ \\
Длительность пребывания больных в ОРИТ, часы & $68,7 \pm 19,2 * *$ & $107,2 \pm 16,2 * *$ \\
\hline
\end{tabular}

Примечание. ${ }^{*}-p<0,05$ между (I) и (IA); ** $-p<0,01$ между (I) и (IA).

Таблица 5

Изменения содержания ВНСММ в плазме и в эритроцитах смешанной венозной и артериальной крови и моче во II группе ( $n=12)$ с использованием перфторана и цитофлавина (ПЦ) в сравнении с IIА группой $(n=12)$ больных без использования перфторана и цитофлавина $(M \pm m)$

\begin{tabular}{|c|c|c|c|c|c|}
\hline \multirow[t]{2}{*}{ Показатель } & \multicolumn{5}{|c|}{ Значение показателей на этапах исследования } \\
\hline & Норма & До ПЦ & После ПЦ & 2-е сутки & 3-и сутки \\
\hline Вена эр. (II) & $22 \pm 3$ & $55,1 \pm 3,6^{\# \#}$ & $42,2 \pm 2,1^{\# \# *}$ & $37,4 \pm 2,7$ \#\#*^ & 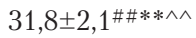 \\
\hline Вена эр. (IIA) & & $52,5 \pm 3,9$ \#\# & & $55,6 \pm 3,8^{\# \# \wedge}$ & $51,1 \pm 2,4^{\# \# \wedge \wedge}$ \\
\hline Арт. эр. (II) & $20 \pm 1,5$ & $57,8 \pm 5,5^{\# \#}$ & $43,7 \pm 3,5^{\# \# * *}$ & $35,4 \pm 3,1^{\# * \wedge *}$ & $30,2 \pm 3,2^{\# * * \wedge \wedge}$ \\
\hline Арт. эр. (IIA) & & $52,5 \pm 3,5^{\# \#}$ & & $51,9 \pm 2,5^{\# \# \wedge}$ & $53,5 \pm 3,2^{\# \# \wedge \wedge}$ \\
\hline Моча (II) & $33 \pm 5$ & $29,8 \pm 4,8$ & $39,8 \pm 3,2$ & $46,8 \pm 4,2^{* \wedge}$ & $45,1 \pm 3,9^{* \wedge \wedge}$ \\
\hline Моча (IIA) & & $31,1 \pm 3,8$ & & $26,6 \pm 5,6^{* \wedge}$ & $24,4 \pm 7,7^{* \wedge \wedge}$ \\
\hline
\end{tabular}

Примечание. ${ }^{*}-$ различия с нормой достоверны $(p<0,05) ;^{*}-$ различия с исходными данными достоверны $(p<0,05){ }^{\wedge}-$ различия (II) группы от (IIA) $(p<0,05)$.

острых отравлений. В группе с применением цитофлавина сокращалась длительность коматозного состояния, сроки нахождения больных в критическом состояния и в стационаре (табл. 4).

В настоящее время большое количество авторов в терапии гипоксии и эндотоксикоза отдают предпочтение инфузионным растворам с кислородтранспортными функциями [3, 24]. Были проведены исследования у 12 больных в критическом состоянии с острыми отравлениями нейротропными средствами. Показаниями для инфузии перфторана являлись критические нарушения транспорта кислорода и наличие эндотоксикоза. Применение перфторана позволило снизить степень нарушений транспорта кислорода уже через 1 час после его инфузии за счет улучшения респираторного и гемического компонентов, следствием чего являлось улучшение процессов доставки кислорода в клетку с 422,5 $\pm 63,7$ до $545,5 \pm 63,2$ мл• м $^{-1}$. Параллельно с выявленными изменениями было отмечено влияние данного препарата на показатели эндотоксемии. Через 1 час после инфузии препарата наблюдали снижение факторов токсемии в глобулярном секторе, с одновременным их увеличением в плазме и в моче. Полученные данные свидетельствуют о том, насколько важно снижение уровня эндотоксинов на эритроцитах, как одного из факторов увеличения кислородной емкости крови (табл. 5).

На наш взгляд, это явилось ведущим механизмом снижения уровня гипоксии тканей, что подтверждалось динамикой изменений уровня лактата в исследуемой группе больных. На 2-е сутки в группе с использованием перфторана и цитофлавина отмечали снижение уровня

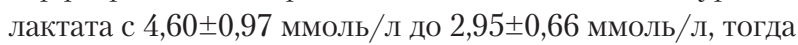
как в группе без использования корректоров доставки кислорода и тканевого метаболизма уровень лактата с 4,01 0,57 ммоль/л имел тенденцию к дальнейшему рос-

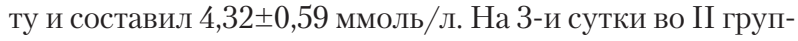
пе продолжала сохраняться тенденция к снижению уровня лактата и значения составили 2,31 $\pm 0,57$ ммоль/л ( при показателях здоровых доноров $-1,11 \pm 0,24)$, тогда как в группе IIA сохранялся повышенный уровень лактата и составлял $4,12 \pm 0,45$ ммоль/л.

Таким образом, при критических состояниях, связанных с острыми отравлениями ядами нейротропного действия терапия должна носить комплексный характер, наряду с максимально быстрым и эффективным снижением уровня экзотоксикоза, чрезвычайно важно применение корректоров доставки кислорода и вслед за чем активная коррекция нарушений метаболических процессов.

\section{Выводы}

1. В патогенезе нарушений транспорта кислорода имеет значение, наряду со специфическими механизмами действия ядов, эндотоксикоз и нарушения метаболических процессов в организме.

2. В коррекции транспорта кислорода, снижения эндотоксикоза и восстановления метаболических процессов у больных в критических состояниях наибольший эффект достигается путем сочетанного применения препаратов перфторана и цитофлавина. 


\section{Литература}

1. Ильяшенко К. К. Кислородотранспортная функция крови у больных с острыми отравлениями. Анестезиология и реаниматология 1995; 3 : $20-22$.

2. Ильященко К. К. Токсическое поражение дыхательной системы при острых отравлениях и его лечение: автореф. дис. ... д-ра мед. наук. М.; 1997.

3. Калмансон М. Л. Гипоксия и ее коррекция у больных с острыми отравлениями ядами нейротропного действия: автореф. дис. ... д-ра мед. наук. СПб.; 2001.

4. Лужников $E$. A. Неотложная терапия острых отравлений и эндотоксикозов. М.: Медицина; 2001. 303.

5. Лужников А. Е., Гольдфарб Ю. С. Коррекция нарушений химического гомеостаза при острых экзогенных отравлениях. Эфферентная терапия 1995; 1 (3): 3-12.

6. Лужников Е. А., Дагаев В. Н. Критические расстройства гомеостаза при острых отравления. В кн.: Сб. науч. тр. Моск. НИИ скорой помощи. М.; 1988; 74. 5-14.

7. Малахова М. Я. Метод регистрации эндогенной интоксикации. СПб. МАПО; 1995.

8. Биленко М. В. Ишемические и реперфузионные повреждения органов: (Молекуляр. механизмы, пути предупреждения и лечения). М. Медицина; 1989

9. Биленко М. В., Шеленкова Л. Н., Дубур Г. Я., Велена А. Х. Применение антиоксидантов для профилактики повреждений при острой ишемии и реперфузии почек. Бюл. эксперим. биологии 1983; 9: 8-9.

10. Жданов Г. Г., Нодель М. Л. Проблема гипоксии у реанимационных больных в свете свободнорадикальной теории. Анестезиология и реаниматология 1995; 1: 53-61.

11. Каган B. E. Механизмы структурно-функциональной модификации биомембран при перекисном окислении липидов: автореф. дис. ... д-ра мед. наук. М.; 1981.

12. Глушков С. И. Сравнительная оценка состояния системы глутатиона в различных органах и тканях при острых пероральных отравлениях дихлорэтаном: автореф. дис. ... канд. мед. наук. СПб.; 1998

13. Досон Р., Эллиот Д., Эллиот У., Джонс К. Справочнник биохимика: Пер.с англ. М.: Мир; 1991.
14. Онуфриев М. В., Лазарева Н. А., Михалев С. Л. и др. Коррекция нарушений свободнорадикальных процессов в мозге крыс в постреанимационном периоде сукцинатом натрия . Бюл. эксперим. биологии и медицины 1994; 2: 214-215.

15. Ливанов Г. А., Куценко С. А., Ивнищкий Ю. Ю. и др. Отчет по доклиническому исследованию терапевтической активности цитофлавина при острой интоксикации барбитуратами. СПб.; 2001.

16. Ливанов Г. А., Куценко С. А., Глушков С. И. и др. Влияние Реамберина на течение острых отравлений нейротропными ядами. В кн.: Исаков В. А., Сологуб Т. В., Коваленко А. Л., Романцов М. Г. Реамберин в терапии критических состояний: руководство для врачей. Изд. 3-е, доп. СПб.: СП Минимакс; 2001. 87-126.

17. Владыка А. С., Левицкий Э. Р., Поддубная Л. П., Габриэлян Н. И. Средние молекулы и проблема эндогенной интоксикации при критических состояниях различной этиологии. Анестезиология и реаниматология 1987; 2: 3-9.

18. Габриелян Н. И., Левицкий Э. Р., Щербакова О. И. и др. Гипотеза средних молекул в практике клинической нефрологии. Терапевт. архив 1983; 6: 76-78.

19. Оболенский С. В., Малахова М. Я. Лабораторная диагностика интоксикаций в практике интенсивной терапии. СПб.; 1991. 16

20. Оболенский С. В. Острая легочная паренхиматозная недостаточность: автореф. дис. ... д-ра мед. наук. СПб.; 1993.

21. Ерюхин И. А., Шашков Б. В. Эндотоксикоз в хирургической клинике. СПб.: Logos; 1995

22. Ерюхин И. А., Шашков Б. В., Лебедев В. Ф. и др. Эндотоксикоз при тяжелой механической травме. В кн.: Детоксикационная терапия при травматической болезни и острых хирургических заболеваниях. Л.; 1989. $9-16$

23. Пасхина Т. С., Долгина М. И., Нартикова В. Ф. и дp. Влияние поливалентного ингибитора протеиназ из легких быка на состояние кининовой системы при ожоговом шоке и ожоговой токсемии. Вопр. мед. химии 1976; 22 (5): 17-19.

24. Мороз В. В. Возможности коррекции гипоксии критических состояний. В кн.: Экспериментальные, клинические и организационные проблемы общей реаниматологии. Сб. тр. НИИ ОР РАМН. М.; 1996. 229-248.

25. Рябов Г. А. Гипоксия критических состояний. М.: Медицина; 1988.

Поступила 08.06.06 